\title{
High glucose-induced resistance to 5-fluorouracil in pancreatic cancer cells alleviated by 2-deoxy-D-glucose
}

\author{
YAO CHENG ${ }^{*}$, DONGMEI DIAO* , HAO ZHANG, QI GUO, \\ XUANDI WU, YONGCHUN SONG and CHENGXUE DANG \\ Department of Surgical Oncology, The First Affiliated Hospital, Xi'an Jiaotong \\ University College of Medicine, Xi'an, Shaanxi 710061, P.R. China
}

Received October 07, 2013; Accepted October 22, 2013

DOI: $10.3892 /$ br.2013.211

\begin{abstract}
Abnormal glucose metabolism from hyperglycemia or diabetes aggravates the progression of pancreatic cancer. It is unknown whether high glucose has an impact on the antitumor effect of 5-fluorouracil (5-Fu) and whether targeting aberrant glucose metabolism using 2-deoxy-Dglucose (2-DG) may reverse this effect in high-glucose microenvironments. The cell viability of AsPC-1 and Panc-1 was analyzed by MTT assay following 5-Fu treatment at different glucose concentrations. Altered sensitivity to $5-\mathrm{Fu}$ by 2-DG was also analyzed. LY294002 was used to inhibit PI3K-Akt signaling to determine the mechanism involved. In response to glucose, 5-Fu-induced cell growth inhibition was attenuated in a dose-dependent manner, accompanied with activated p-Akt, while 2-DG enhanced 5-Fu-induced cell growth inhibition. Moreover, blocking the PI3K/Akt pathway by LY294002 effectively eliminated 2-DG-induced apoptosis. In conclusion, high glucose weakens the antitumor effect of 5-Fu via PI3K/Akt signaling. Using 2-DG in combination with 5-Fu significantly increased their therapeutic effectiveness in high-glucose microenvironments.
\end{abstract}

\section{Introduction}

Pancreatic cancer is a globally lethal human disease, with an overall 5-year survival rate of $<4 \%$ (1), and a median survival period of 4-6 months $(2,3)$. It is considered the fourth leading cause of cancer mortality in males and females (4). The nucleoside analog of cytidine 5-fluorouracil (5-Fu) is widely used

Correspondence to: Dr Chengxue Dang, Department of Surgical Oncology, The First Affiliated Hospital, Xi'an Jiaotong University College of Medicine, 277 West Yanta Road, Xi'an, Shaanxi 710061, P.R. China

E-mail: dangchengxue@mail.xjtu.edu.cn

*Contributed equally

Key words: pancreatic cancer, glucose, 5-fluorouracil, 2-deoxy-D-glucose in the treatment of advanced gastrointestinal cancer, including pancreatic cancer (5-7).

However, only few patients benefit from 5-Fu-based chemotherapy. Intrinsic or acquired resistance to chemotherapy is a leading cause of treatment failure and short survival time $(8,9)$. The reasons for the insensitivity of pancreatic cancer cells to chemotherapy and the molecular mechanisms that enable pancreatic cancer cells to escape the cytotoxic effects have yet to be determined (10-12).

Abnormal biochemical characteristics associated with pancreatic cancer cells include the increased utilization of glucose (13). Increased proliferation depends on abnormal glucose metabolism for the generation of ATP as a main source of energy supply as most cancer cells lack oxidative phosphorylation. This phenomenon is known as the Warburg effect (14-18). This metabolic alteration is frequently observed in cancer cells of various tissue origins, thus targeting the glycolytic pathway may preferentially kill the malignant cancer cells but spare normal cells.

Previously, we demonstrated that PI3K-Akt activated by NGF-TrkA signaling was involved in the resistance to chemotherapy (19). Akt may be considered as the 'Warberg gene' (20), which is closely associated with tumor glycolysis and glucose utilization. Since pancreatic cancer cells demonstrate increased utilization of glucose, it is crucial to target glycolysis metabolic pathway for the treatment of pancreatic cancer.

To examine whether high glucose plays a role in the resistance to $5-\mathrm{Fu}$ and whether the inhibition of glycolysis using glycolysis inhibitor 2-deoxy-D-glucose (2-DG) results in enhanced sensitivity to $5-\mathrm{Fu}$, we investigated cell viability by $5-\mathrm{Fu}$ treatment on different concentrations of glucose in AsPC-1 and Panc-1 pancreatic cancer cells. Additionally, we investigated whether $2-\mathrm{DG}$ is able to reverse high glucose-induced 5-Fu resistance via PI3K-Akt signaling.

\section{Materials and methods}

Reagents. 5-Fu, dimethyl sulfoxide (DMSO), 2-DG, glucose and 3-(4,5-dimethylthiazol-2-yl)-2,5-diphenyltetrazolium bromide (MTT) were purchased from Sigma-Aldrich (St. Louis, MO, USA). RIPA buffer and PMSF were purchased from Beyotime (Haimen, Jiangsu, China). Anti-p-Akt and PI3K inhibitor LY294002 were purchased from Abcam (Cambridge, 
MA, USA). Anti- $\beta$-actin antibody was from Abnova (Taiwan, China).

Cell culture. Human pancreatic cancer AsPC-1 and Panc-1 cells were purchased from the Type Culture Collection of the Chinese Academy of Sciences (Shanghai, China). The cells were grown in RPMI-1640 medium (Gibco, Carlsbad, CA, USA) supplemented with $10 \%$ heat-inactivated FBS (Hyclone, Logan, UT, USA), penicillin $100 \mathrm{U} / \mathrm{ml}$ and streptomycin $100 \mu \mathrm{g} / \mathrm{ml}$ (Gibco). The cultures were maintained at $37^{\circ} \mathrm{C}$ in a $5 \% \mathrm{CO}_{2}$ incubator.

Cell growth inhibition assay. Cell viability was assessed via an MTT assay. ASPC-1 and Panc-11 cells were seeded (3,000/well) in 96-well plates for $24 \mathrm{~h}$. Media containing 5-Fu, 2-DG, LY294002 or control medium were added and incubated for the indicated times at $37^{\circ} \mathrm{C}$. MTT $(0.5 \mathrm{mg} / \mathrm{ml}$ in PBS $)$ was added to each well and incubated for $4 \mathrm{~h}$ at $37^{\circ} \mathrm{C}$. The media were then discarded and $100 \mu \mathrm{l}$ DMSO was added. Following agitation for $10 \mathrm{~min}$ on an eppendorf shaker, absorbance was read at $550 \mathrm{~nm}$ on a scanning microtiter. Data were expressed relative to the untreated group, which was set as $100 \%$.

Western blot analysis. Cells were lysed with modified RIPA buffer $(50 \mathrm{mM}$ Tris, $150 \mathrm{mM} \mathrm{NaCl}, 1 \%$ Triton X-100, $1 \%$ sodium deoxycholate, $0.1 \%$ SDS) containing $25 \mu \mathrm{g} / \mathrm{ml}$ leupeptin, $1 \mathrm{mM}$ sodium orthovanadate, $2 \mathrm{mM}$ EDTA, and $1 \mathrm{mM}$ PMSF. The protein concentration was determined using a BCA method (Beyotime). Twenty micrograms of proteins per sample were loaded onto $8 \%$ SDS-polyacrylamide gel, electrophoresed, and blotted onto PVDF membrane. Proteins were probed with the primary antibody overnight at $4^{\circ} \mathrm{C}$ and secondary antibody at room temperature for $1 \mathrm{~h}$. Immunoreactivity was detected by the ECL system (Xi'an Jiaotong University, China) and normalized to $\beta$-actin.

Statistical analysis. Data were analyzed by SPSS 13.0 using t-test. $\mathrm{P}<0.05$ was considered statistically significant.

\section{Results}

High-glucose microenvironments alleviated 5-Fu-induced cell growth inhibition. To investigate the influence of glucose levels on resist to 5-Fu, cells were incubated in a series of gradually increasing glucose concentrations for $72 \mathrm{~h}$ with $1 \mathrm{mM}$ of 5 -Fu.

Increased cell growth of AsPC-1 and Panc-1 cells treated with 5-Fu was observed in response to the glucose concentrations ranging from 5.6 to $25 \mathrm{mM}$. In AsPC-1 and Panc-1 cells, the cell viability rate was increased in a dose-dependent manner at glucose concentrations of $5.6 \mathrm{mM}$ (as a control) to $25 \mathrm{mM}$, at $72 \mathrm{~h}$, respectively ( $\mathrm{P}<0.05)$ (Fig. 1). In comparison with parental ASPC-1 and Panc-1, incubation with 5-Fu for $72 \mathrm{~h}$ at the glucose concentration of $5.6 \mathrm{mM}$ decreased the cell number to 28 and $31 \%$, respectively $(\mathrm{P}<0.05)$. High-glucose microenvironments showed a marked effect on the growth of AsPC-1 and Panc-1 cells. At the glucose concentration of $25 \mathrm{mM}, 5-\mathrm{Fu}$ decreased the cell number to 55 and $72 \%$, respectively $(\mathrm{P}<0.05)$. The cytotoxic effect of 5 -Fu reduced glucose in a concentration-dependent manner.
2-DG enhanced cytotoxic effects of 5-Fu in high-glucose microenvironments. Several studies demonstrated that 2-DG induces cell growth inhibition and death in pancreatic cancer cells by interfering with glucose metabolism. We hypothesized that the enhanced resistance to $5-\mathrm{Fu}$ in glucose microenvironments may be blocked by the anti-glucose metabolism treatment of 2-DG. To test this, 2-DG (10 mM) was used to interfere with cell glucose metabolism and detect the sensitivity of the two cell responses to 5-Fu treatment at the glucose concentration of $25 \mathrm{mM}$. Growth of AsPC-1 and Panc-1 was inhibited by incubation with 5-Fu or 2-DG alone in a time-dependent manner $(\mathrm{P}<0.05)$. Treatment of tumor cells with $0.5 \mathrm{mM} 5$-Fu combined with $5 \mathrm{mM}$ 2-DG revealed a marked decreased in cell growth compared with 5-Fu or 2-DG alone $(\mathrm{P}<0.05)$, leading to a decrease of $54 \%$ in AsPC- 1 and $52 \%$ in Panc-1 at $72 \mathrm{~h}$ of incubation (Fig. 2).

2-DG enhanced 5-Fu cytotoxic effect depending on PI3K signaling. Treatment of AsPC-1 and Panc-1 cells with $10 \mathrm{mM}$ 2-DG resulted in $\sim 38$ and $41 \%$ inhibition of cell growth, respectively, in a time-dependent manner. Three concentrations $(6.1,7.8$ and $25 \mathrm{mM})$ of glucose were selected to detect the expression of Akt, also known as the Wurberg gene and to determine whether it can be inhibited by 2-DG (Fig. 3A). As cells incubated with higher concentrations of glucose exhibited increased activity of p-Akt, we examined whether the upregulation of Akt by glucose is important in 2-DG-induced cell growth. Consequently, we treated cells with LY294002 and found that LY294002 significantly attenuated the death of 2-DG-induced cells (Fig. 3B and C). The combination of 5-Fu and 2-DG did not exhibit any significance compared with 5-Fu alone. Although 2-DG reduced the expression of Akt, blocking PI3K/Akt signaling using LY294002 did not enhance the inhibition of 5-Fu.

\section{Discussion}

2-DG is a glucose analog and acts as a competitive inhibitor of glucose metabolism, causing a depletion of cellular ATP (21), leading to blockage of cell cycle progression (22), and inducing cell death (23). In addition, 2-DG inhibits protein glycosylation, and induces the accumulation of misfolded proteins in the endoplasmic reticulum, leading to endoplasmic reticulum stress response and constant cell apoptosis (24). 2-DG has been proven to be an anti-cancer drug for a variety of cancer cells and increases the efficacy of radiotherapy and chemotherapy agents such as adriamycin and paclitaxel $(25,26)$.

In the present study, we used glucose as a model to enhance cell resistance to the widely used anti-pancreatic cancer agent 5-Fu in AsPC-1 and Panc-1 pancreatic cancer cells. The results demonstrated that active PI3K-Akt by high-glucose concentrations decreased the antitumor effect of $5-\mathrm{Fu}$, which is in agreement with previous studies $(19,27-31)$. Of note, 2-DG significantly reversed the resistance to $5-\mathrm{Fu}$ in $25 \mathrm{mM}$ of glucose. Our data demonstrated that PI3K-Akt is required for 2-DG-induced cell growth inhibition. Similarly, enhanced proliferation due to NGF-TrkA signaling or loss of PTEN makes cells more sensitive to 2-DG $(32,33)$.

Our results emphasize that an increase in blood sugar as a result of diabetes, which is closely associated with pancreatic 


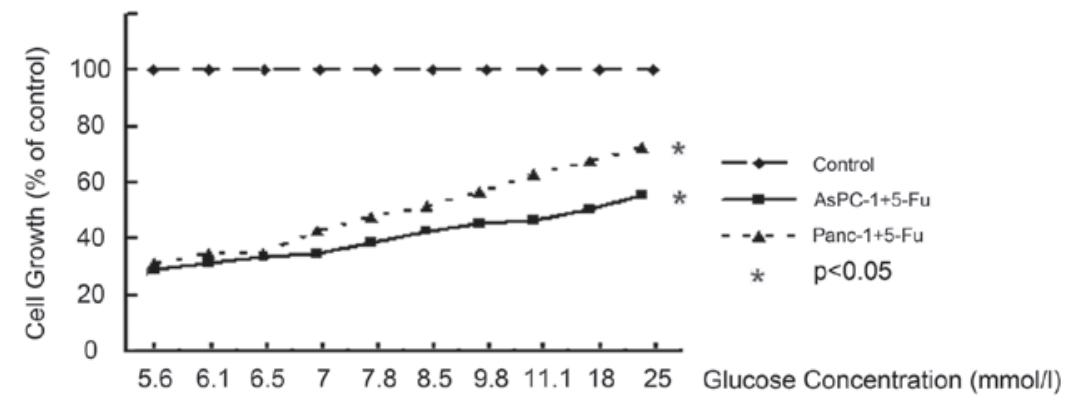

Figure 1. MTT conversion following treatment with 5-fluorouracil (5-Fu). AsPC-1 and Panc-1 cells were incubated with $1 \mathrm{mM} \mathrm{5-Fu} \mathrm{for} 72 \mathrm{~h}$ at different concentrations of glucose varying from 5.6 to $25 \mathrm{mM}$, which mimic different blood sugar levels of patients. MTT was added and determined spectrophotometrically at $72 \mathrm{~h}$. High glucose showed an increased effect on the growth of two cell types at $72 \mathrm{~h}$. Results are expressed as the percentage of control cells without incubation with 5 -Fu at $72 \mathrm{~h}$ of glucose, respectively.

A

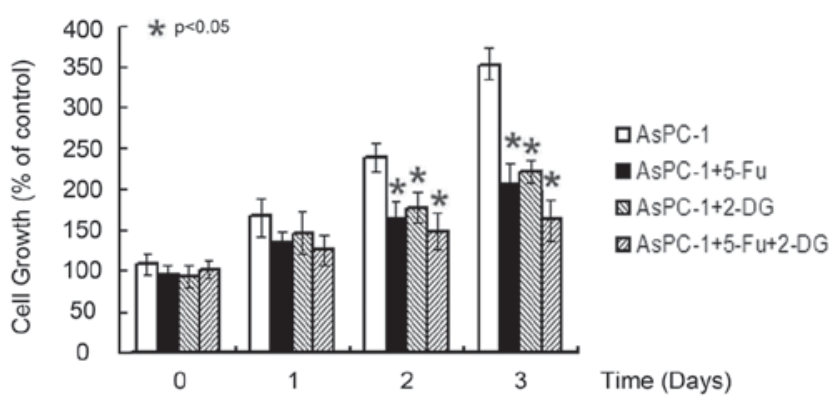

B

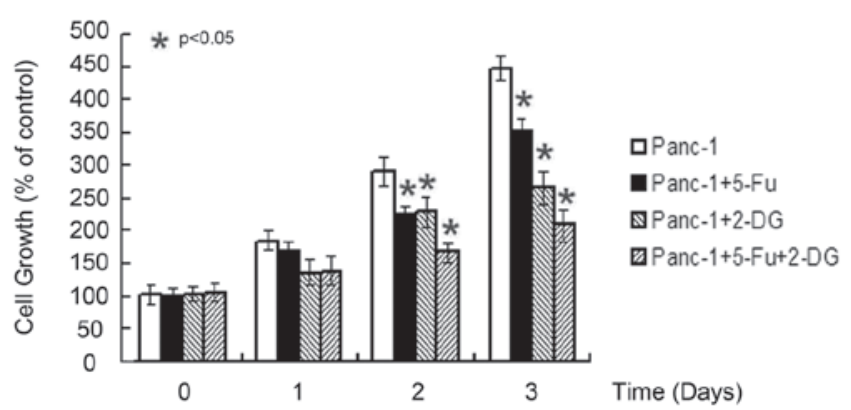

Figure 2. 2-Deoxy-D-glucose (2-DG) combined with 5-fluorouracil (5-Fu) significantly inhibited the growth of two types of cells at $25 \mathrm{mM}$ of glucose in a time-dependent manner. Following incubation with 2-DG, AsPC-1 and Panc-1 expressed marked growth inhibition. Half dose of 2-DG combined with half dose of 5-Fu significantly inhibited the growth of the two cell types compared with using each agent alone.

cancer may increase the risk of cancer proliferation and resistance to chemotherapy (34-37). Controlling blood sugar levels is significant in the therapy of pancreatic cancer. However, this resistance can be alleviated by glycolysis inhibition using 2-DG. Our results suggest that targeting glucose glycolysis is a viable approach for the development of anti-cancer drugs, particularly for patients experiencing difficulty in reducing blood sugar levels.

Activation of the PI3K/AKT pathway has been implicated in a variety of tumors $(38,39)$, mediating tumor growth, and exhibiting resistance to apoptosis and chemotherapy. PI3K/AKT pathway inhibition leads to a wide spectrum of direct effects including cell cycle arrest, induction of autophagy, sensitization to chemotherapeutics, inhibition of
A
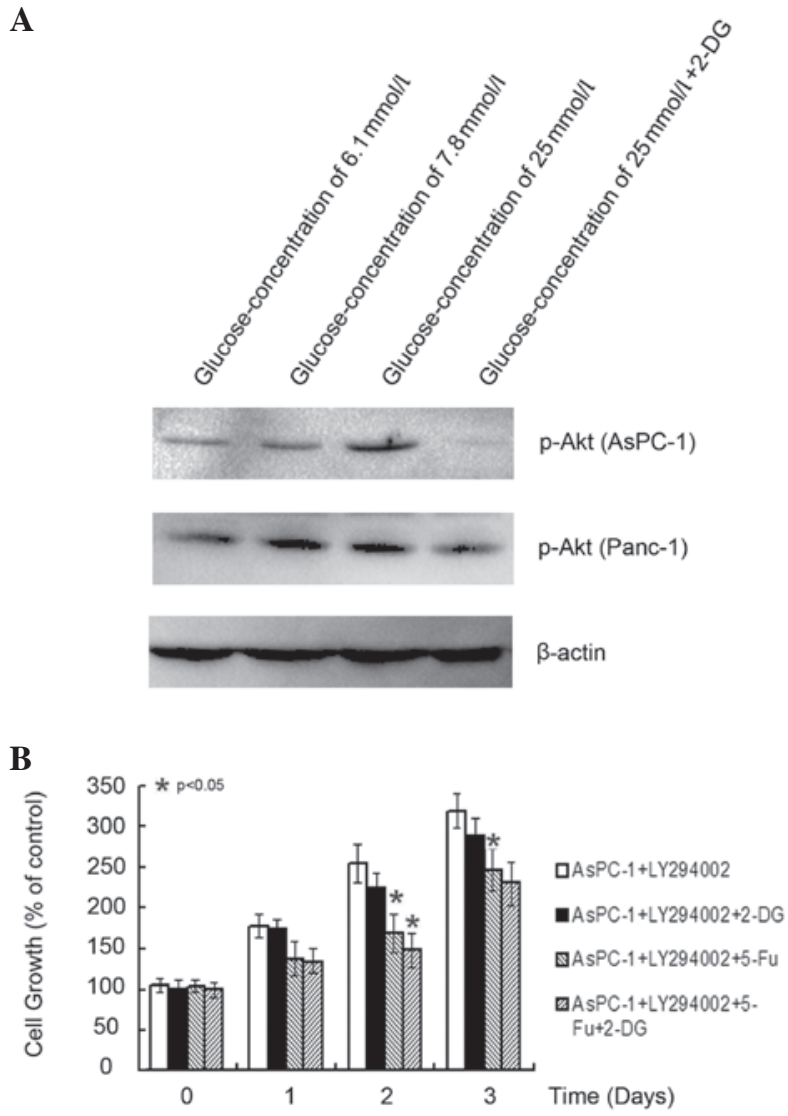

C

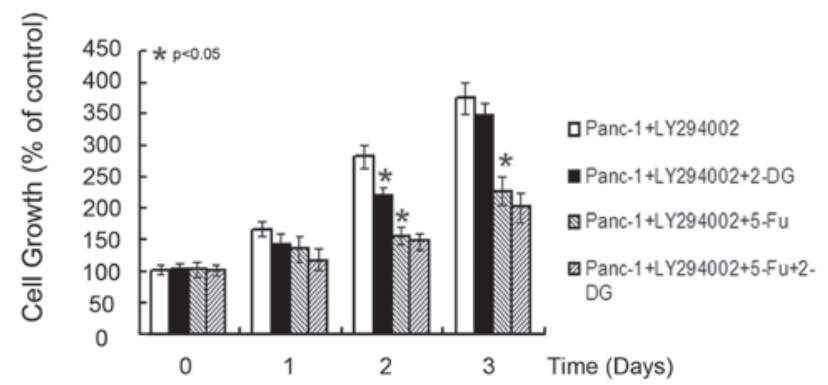

Figure 3. PI3K/Akt is involved in glucose-induced resistance to 5-fluorouracil (5-Fu). (A) p-Akt is upregulated at high versus low concentrations of glucose, a phenomenon blocked by using 2-deoxy-D-glucose (2-DG). (B and C) Via inhibition of PI3K/Akt with LY294002 in AsPC-1 and Panc-1 cells, the growth inhibition by 2-DG was greatly alleviated, although not equal to the condition without LY294002. This phenomenon did not occur in the treatment with 5-Fu, thus 2-DG increased the effect of 5-Fu via PI3K/Akt signaling, although not only by blocking this pathway. 
metastasis as well as cell differentiation and death $(40,41)$. Results of the present study have shown that glucose and 2-DG were involved in the regulation of PI3K/Akt signaling, and this may explain the effect of aberrant glucose metabolism in pancreatic cancer, and highlight the marked efficiency of 2-DG in high-glucose microenvironments and the significance of controlling the blood sugar of pancreatic cancer patients, particularly those with diabetes. However, blocking PI3K/Akt did not provide an adequate explanation for the entire mechanism of 2-DG, or the effect of 5-Fu being greatly enhanced by using LY294002. Thus additional studies should be conducted to further elucidate the mechanism involved.

In conclusion, the results of the present study demonstrated that the effect of 5-Fu-based chemotherapy on pancreatic cancer is significantly reduced by high glucose, although this effect can be reversed by 2-DG. It is therefore crucial for pancreatic cancer patients to control blood sugar levels in order to fully benefit from chemotherapy.

\section{Acknowledgements}

This study was funded by the National Natural Science Foundation of China, NSFC (grant no. 30973489).

\section{References}

1. Vincent A, Herman J, Schulick R, Hruban RH and Goggins M: Pancreatic cancer. Lancet 378: 607-620, 2011.

2. Dubecz A, Kohler J and Stein HJ: Cholecystectomy in a trial of adjuvant chemotherapy after pancreatic cancer resection. JAMA 304: 2590; author reply 2590-2591, 2010.

3. Torpy JM, Burke AE and Glass RM: JAMA patient page. Pancreatic cancer. JAMA 304: 1140, 2010.

4. Siegel R, Ward E, Brawley O and Jemal A: Cancer statistics, 2011: the impact of eliminating socioeconomic and racial disparities on premature cancer deaths. CA Cancer J Clin 61: 212-236, 2011

5. Gu WJ and Liu HL: Induction of pancreatic cancer cell apoptosis, invasion, migration, and enhancement of chemotherapy sensitivity of gemcitabine, 5-FU, and oxaliplatin by hnRNP A2/B1 siRNA. Anticancer Drugs 24: 566-576, 2013.

6. Bhattacharyya M, Francis J, Eddouadi A, Lemoine NR and Hallden G: An oncolytic adenovirus defective in pRb-binding (d1922-947) can efficiently eliminate pancreatic cancer cells and tumors in vivo in combination with 5-FU or gemcitabine. Cancer Gene Ther 18: 734-743, 2011

7. Oberic L, Viret F, Baey C, Ychou M, Bennouna J, Adenis A, Peiffert D, Mornex F, Pignon JP, Celier P, Berille J and Ducreux M: Docetaxel- and 5-FU-concurrent radiotherapy in patients presenting unresectable locally advanced pancreatic cancer: a FNCLCC-ACCORD/0201 randomized phase II trial's pre-planned analysis and case report of a 5.5-year disease-free survival. Radiat Oncol 6: 124, 2011.

8. Ischenko I, Seeliger H, Jauch KW and Bruns CJ: Metastatic activity and chemotherapy resistance in human pancreatic cancer - influence of cancer stem cells. Surgery 146: 430-434, 2009.

9. Zhang C, Kolb A, Buchler P, Cato AC, Mattern J, Rittgen W, Edler L, Debatin KM, Buchler MW, Friess H and Herr I: Corticosteroid co-treatment induces resistance to chemotherapy in surgical resections, xenografts and established cell lines of pancreatic cancer. BMC Cancer 6: 61, 2006.

10. Liu QH, Zhang J, Zhao CY, Yu DH, Bu HJ, Chen Y, Ni CY and Zhu MH: Surviving cells after treatment with gemcitabine or 5 -fluorouracil for the study of de novo resistance of pancreatic cancer. Cancer Lett 314: 119-125, 2012.

11. Tsujie M, Nakamori S, Nakahira S, Takahashi Y, Hayashi N, Okami J, Nagano H, Dono K, Umeshita K, Sakon M and Monden M: Human equilibrative nucleoside transporter 1, as a predictor of 5-fluorouracil resistance in human pancreatic cancer. Anticancer Res 27: 2241-2249, 2007.
12. Shi X, Liu S, Kleeff J, Friess H and Buchler MW: Acquired resistance of pancreatic cancer cells towards 5-fluorouracil and gemcitabine is associated with altered expression of apoptosisregulating genes. Oncology 62: 354-362, 2002.

13. Coleman MC, Asbury CR, Daniels D, Du J, Aykin-Burns N, Smith BJ, Li L, Spitz DR and Cullen JJ: 2-deoxy-D-glucose causes cytotoxicity, oxidative stress, and radiosensitization in pancreatic cancer. Free Radic Biol Med 44: 322-331, 2008.

14. Nam SO, Yotsumoto F, Miyata K, Shirasu N, Miyamoto S and Kuroki M: Possible therapeutic targets among the molecules involved in the Warburg effect in tumor cells. Anticancer Res 33: 2855-2860, 2013.

15. Dang CV: Rethinking the Warburg effect with Myc micromanaging glutamine metabolism. Cancer Res 70: 859-862, 2010.

16. Kim JW and Dang CV: Cancer's molecular sweet tooth and the Warburg effect. Cancer Res 66: 8927-8930, 2006.

17. Samudio I, Fiegl M and Andreeff M: Mitochondrial uncoupling and the Warburg effect: molecular basis for the reprogramming of cancer cell metabolism. Cancer Res 69: 2163-2166, 2009.

18. Samudio I, Fiegl M, McQueen T, Clise-Dwyer K and Andreeff M: The Warburg effect in leukemia-stroma cocultures is mediated by mitochondrial uncoupling associated with uncoupling protein 2 activation. Cancer Res 68: 5198-5205, 2008.

19. Liu D, Zhang Y, Dang C, Ma Q, Lee W and Chen W: siRNA directed against TrkA sensitizes human pancreatic cancer cells to apoptosis induced by gemcitabine through an inactivation of PI3K/Akt-dependent pathway. Oncol Rep 18: 673-677, 2007.

20. Robey RB and Hay N: Is Akt the 'Warburg kinase'?-Akt-energy metabolism interactions and oncogenesis. Semin Cancer Biol 19: 25-31, 2009.

21. Aft RL, Zhang FW and Gius D: Evaluation of 2-deoxy-D-glucose as a chemotherapeutic agent: mechanism of cell death. Br J Cancer 87: 805-812, 2002.

22. Pelicano H, Martin DS, Xu RH and Huang P: Glycolysis inhibition for anticancer treatment. Oncogene 25: 4633-4646, 2006.

23. Ben Sahra I, Laurent K, Giuliano S, Larbret F, Ponzio G, Gounon P, Le Marchand-Brustel Y, Giorgetti-Peraldi S, Cormont M, Bertolotto C, Deckert M, Auberger P, Tanti JF and Bost F: Targeting cancer cell metabolism: the combination of metformin and 2-deoxyglucose induces p53-dependent apoptosis in prostate cancer cells. Cancer Res 70: 2465-2475, 2010.

24. Kurtoglu M, Gao N, Shang J, Maher JC, Lehrman MA, Wangpaichitr M, Savaraj N, Lane AN and Lampidis TJ: Under normoxia, 2-deoxy-D-glucose elicits cell death in select tumor types not by inhibition of glycolysis but by interfering with N-linked glycosylation. Mol Cancer Ther 6: 3049-3058, 2007.

25. Aft RL, Lewis JS, Zhang F, Kim J and Welch MJ: Enhancing targeted radiotherapy by copper(II)diacetyl- bis(N4-methylthiosemicarbazone) using 2-deoxy-D-glucose. Cancer Res 63: 5496-5504, 2003.

26. Maschek G, Savaraj N, Priebe W, Braunschweiger P, Hamilton K, Tidmarsh GF, De Young LR and Lampidis TJ: 2-deoxy-D-glucose increases the efficacy of adriamycin and paclitaxel in human osteosarcoma and non-small cell lung cancers in vivo. Cancer Res 64: 31-34, 2004

27. Chen Y, Wang Z, Chang P, Xiang L, Pan F, Li J, Jiang J, Zou L, Yang L, Bian $\mathrm{Z}$ and Liang $\mathrm{H}$ : The effect of focal adhesion kinase gene silencing on 5-fluorouracil chemosensitivity involves an $\mathrm{Akt} / \mathrm{NF}-\mathrm{kappaB}$ signaling pathway in colorectal carcinomas. Int J Cancer 127: 195-206, 2010.

28. You F, Aoki K, Ito Y and Nakashima S: AKT plays a pivotal role in the acquisition of resistance to 5 -fluorouracil in human squamous carcinoma cells. Mol Med Rep 2: 609-613, 2009.

29. Upadhyay AK, Singh S, Chhipa RR, Vijayakumar MV, Ajay AK and Bhat MK: Methyl-beta-cyclodextrin enhances the susceptibility of human breast cancer cells to carboplatin and 5-fluorouracil: involvement of Akt, NF-kappaB and Bcl-2. Toxicol Appl Pharmacol 216: 177-185, 2006.

30. Kodach LL, Bos CL, Duran N, Peppelenbosch MP, Ferreira CV and Hardwick JC: Violacein synergistically increases 5-fluorouracil cytotoxicity, induces apoptosis and inhibits Akt-mediated signal transduction in human colorectal cancer cells. Carcinogenesis 27: 508-516, 2006.

31. Yang H, Ni L, Ma YQ and Song YG: PI3K p85alpha gene silencing by RNA interference promotes 5-fluorouracil-induced apoptosis of colorectal cancer LoVo cells. Nan Fang Yi Ke Da Xue Xue Bao 30: 1085-1088, 2010 (In Chinese). 
32. Cheng $\mathrm{Y}$, Diao DM, Zhang $\mathrm{H}$, Song $\mathrm{YC}$ and Dang $\mathrm{CX}$ Proliferation enhanced by NGF-NTRK1 signaling makes pancreatic cancer cells more sensitive to 2DG-induced apoptosis. Int J Med Sci 10: 634-640, 2013.

33. Blouin MJ,Zhao Y,Zakikhani M, Algire C, Piura E and Pollak M: Loss of function of PTEN alters the relationship between glucose concentration and cell proliferation, increases glycolysis, and sensitizes cells to 2-deoxyglucose. Cancer Lett 289: 246-253, 2010.

34. Mizuno S, Nakai Y, Isayama H, Takahara N, Miyabayashi K, Yamamoto K, Kawakubo K, Mohri D, Kogure H, Sasaki T, Yamamoto N, Sasahira N, Hirano K, Tsujino T, Ijichi H, Tateishi K, Tada M and Koike K: Diabetes is a useful diagnostic clue to improve the prognosis of pancreatic cancer. Pancreatology 13: 285-289, 2013

35. McAuliffe JC and Christein JD: Type 2 diabetes mellitus and pancreatic cancer. Surg Clin North Am 93: 619-627, 2013.

36. Aggarwal G, Kamada P and Chari ST: Prevalence of diabetes mellitus in pancreatic cancer compared to common cancers. Pancreas 42: 198-201, 2013.

37. Mizuno S, Nakai Y, Isayama H, Yanai A, Takahara N, Miyabayashi K, Yamamoto K, Kawakubo K, Mohri D, Kogure H, Sasaki T, Yamamoto N, Sasahira N, Hirano K, Tsujino T, Ijichi H, Tateishi K, Akanuma M, Tada M and Koike K: Risk factors and early signs of pancreatic cancer in diabetes: screening strategy based on diabetes onset age. J Gastroenterol 48: 238-246, 2013.
38. Florena AM, Tripodo C, Guarnotta C, Ingrao S, Porcasi R, Martorana A, Lo Bosco G, Cabibi D and Franco V: Associations between Notch-2, Akt-1 and HER2/neu expression in invasive human breast cancer: a tissue microarray immunophenotypic analysis on 98 patients. Pathobiology 74: 317-322, 2007.

39. Cen B, Mahajan S, Wang W and Kraft AS: Elevation of receptor tyrosine kinases by small molecule akt inhibitors in prostate cancer is mediated by Pim-1. Cancer Res 73: 3402-3411, 2013.

40. Floc'h N, Kinkade CW, Kobayashi T, Aytes A, Lefebvre C, Mitrofanova A, Cardiff RD, Califano A, Shen MM and Abate-Shen C: Dual targeting of the Akt/mTOR signaling pathway inhibits castration-resistant prostate cancer in a genetically engineered mouse model. Cancer Res 72: 4483-4493, 2012.

41. Dansen TB and Burgering BM: Unravelling the tumor-suppressive functions of FOXO proteins. Trends Cell Biol 18: 421-429, 2008. 